\title{
UMA AVALIAÇÃO DA PARTICIPAÇÃO DO BRASIL NAS DIRETRIZES DA OCDE PARA CONDUTA RESPONSÁVEL DE EMPRESAS MULTINACIONAIS
}

Bernardo Mueller ${ }^{1}$

Felipe Roviello²

\begin{abstract}
SINOPSE
As Diretrizes da Organização para a Cooperação e Desenvolvimento Econômico (OCDE) para conduta empresarial responsável oferecem um fórum ao qual grupos e indivíduos podem denunciar violações por parte de empresas multinacionais, assim como mediação entre as empresas denunciadas e os denunciantes na busca de acordos e solução dos conflitos. Com atuação em 49 países, é um dos maiores programas de responsabilidade social corporativa do mundo. Como o programa não tem poder legal de sanção e a participação das empresas é voluntária, ele depende da sua capacidade de dar visibilidade às denúncias e da percepção por parte das empresas dos custos envolvidos por meio de impactos à sua imagem e reputação. Neste trabalho, nós detalhamos os casos mediados pelo Ponto de Contato Nacional (NCP) do Brasil. Realizamos também testes quantitativos por estudos de eventos com dados do mercado acionário e mostramos que há evidência que uma denúncia ao programa efetivamente impõe custos às empresas.
\end{abstract}

Palavras-chave: responsabilidade social corporativa; governança corporativa; OCDE; estudo de eventos; Brasil.

\begin{abstract}
The OECD Guidelines for Responsible Business Conduct provide a forum in which groups and individuals can report violations by multinational companies, and also mediation between reported companies and whistleblowers towards reaching agreements and arbitrating conflicts. Operating in 49 countries, it is one of the largest corporate social responsibility programs in the world. As the program has no legal sanctioning power and the companies' participation is voluntary, it depends on its ability to give visibility to complaints, and also on the perception by companies of the costs and risks to their image and reputation. In this paper we detail the cases mediated by the national contact point (NCP) in Brazil. We also carry out quantitative tests through events studies using stock market data and show evidence that a complaint to the program does effectively imposes costs on the companies.
\end{abstract}

Keywords: corporate social responsibility; corporate governance; OECD; event studies; Brazil.

JEL: M14; G14; F53.

Artigo recebido em 8/2/2021 e aprovado em 5/3/2021.

DOl: http://dx.doi.org/10.38116/bepi29art4

\section{INTRODUÇÃO}

As Diretrizes da Organização para a Cooperaçáo e Desenvolvimento Econômico (OCDE) para conduta responsável de empresas multinacionais compóem um dos maiores programas mundiais de fomento à responsabilidade social corporativa (Corporate Social Responsibility - CRS). Por meio desse programa, estabelecido em 2000 e que hoje conta com a participação de 49 países, indivíduos

1. Professor titular do Departamento de Economia da Universidade de Brasília (UnB).E-mail: <bmueller@unb.br>.

2. Mestrando em economia na UnB. E-mail: <feliperoviello@gmail.com>. 
ou grupos organizados como organizaçóes não governamentais (ONGs) e grupos de advocacia têm um fórum para denunciar açôes ou comportamentos por parte de empresas multinacionais que violem a conduta responsável empresarial, especialmente em áreas ligadas a meio ambiente, direitos humanos, questóes trabalhistas, corrupção e governança em geral. ${ }^{3}$ Com o programa, cada país mantém um Ponto de Contato Nacional (PCN) a quem a denúncia pode ser feita e que media e arbitra uma resoluçáo entre denunciantes e as empresas (OECD, 2016).

Embora trate de temas típicos de CSR, as Diretrizes diferem de açôes usuais nessa área porque a iniciativa parte de uma denúncia formal no bojo de um programa unificado a nível global. Nesse programa, quem inicia um caso é o denunciante e a empresa age reativamente ao decidir se aceita ou não participar do processo de mediação oferecido pelo programa. Os PCNs não possuem poder de sanção e requerem cooperaçáo voluntária da empresa para poder negociar uma resoluçáo. O programa conta, porém, com a visibilidade que ele é capaz de dar a uma denúncia e a percepção por parte das empresas do impacto que isso pode ter sobre a sua imagem e reputação diante da sociedade e dos mercados. Nesse sentido, o programa tem a mesma característica de soft law das quais açóes usuais de CSR também dependem.

A literatura sobre Responsabilidade Social Corporativa tem dois grandes temas dominantes. O primeiro é uma discussão normativa se empresas deveriam ou não adotar ações de CSR. Essa discussão geralmente parte da afirmação de Friedman (2007) que a única responsabilidade social das empresas é aumentar o seu próprio lucro e envolve argumentos sobre ética corporativa e falhas de mercado. O segundo tema dominante envolve determinar quais os impactos efetivos de açóes de responsabilidade social sobre a performance da empresa e também seus impactos no meio ambiente, direitos humanos e outros objetivos do programa. Identificar esses impactos e quantificá-los corretamente é uma tarefa difícil e há muitas críticas no sentido de que boa parte dos esforços das empresas são somente uma questấo de aparências com poucos benefícios concretos para a sociedade.

Neste trabalho, o nosso interesse está no segundo tema dominante. Embora haja bastante escrito sobre o histórico e o funcionamento das Diretrizes da OCDE (Thorstensen, Cortellini e Gullo, 2018; Ruggie e Nelson, 2015; Nieuwenkamp, 2013; Davarnejad, 2011), há ainda uma escassez de tentativas rigorosas de quantificação desse impacto - uma exceção é Weissman et al. (2016). A efetividade do programa depende da publicidade que consegue dar às denúncias e da reação por parte da sociedade e dos mercados a essa informaçáo. Portanto, é crucial para o funcionamento do programa que as empresas tenham a percepção que uma denúncia efetivamente pode gerar custos reputacionais significativos, senão elas poderão simplesmente ignorar as acusaçôes e se recusar a participar sem consequências. Análises descritivas, como em Ruggie e Nelson (2015), mostram que vários casos atingiram grande repercussão e publicidade, no entanto, uma leitura mais sistemática também mostra que um grande número não conseguiu engajar as empresas no processo de mediação. Há, portanto, a necessidade de análises quantitativas mais rigorosas para identificar a existência, natureza e magnitude do impacto de uma denúncia de uma empresa multinacional nas Diretrizes. ${ }^{4}$

Em Mueller e Roviello (s.d.) são usados os preços das ações no mercado acionário para realizar testes de estudos de eventos sobre o universo dos dados de denúncias na base das Diretrizes: em muitos casos, é possível identificar e quantificar um impacto negativo para as empresas denunciadas nesse

3. Para os propósitos das Diretrizes, empresas multinacionais são empresas com operações em mais de um país. Esses princípios se aplicam, portanto, a empresas nacionais de grande porte, como Banco do Brasil, Vale, Natura, Petrobras etc.

4. A base de dados com informações detalhadas sobre cada denúncia está disponível em: <http://mneguidelines.oecd.org/database/>. 
programa. Neste trabalho, fazemos o mesmo, mas focando exclusivamente nas empresas brasileiras que foram denunciadas. Nas bases de dados da OCDE, o PCN do Brasil é o quarto mais ativo, com 31 casos, e o Brasil é o quarto maior hospedeiro de empresas denunciadas, com 33 casos. A questão a ser investigada aqui é se essas empresas sofreram algum impacto por ter recebido as denúncias de terem violado as Diretrizes da OCDE.

Essa questão se reveste de importância adicional devido às pretensôes brasileiras de aceder a membro efetivo da OCDE, pelo menos desde a administração de Fernando Henrique Cardoso (1994-2002) (OECD, 2018). É também uma pretensão da própria OCDE, que vem perseguindo uma estratégia de ampliação de sua influência global através da acessão de novos membros. Em 2006, a organização estabeleceu quatro critérios para avaliar a candidatura de novos países à acessão: deveriam ter like-mindedness (afinidade de ideias e valores); serem atores significativos; a acessão deverá trazer benefícios mútuos; e levar em conta consideraçôes globais geopolíticas. Acima de tudo, o país candidato deverá demonstrar uma participação ativa nos fóruns e programas da OCDE, conforme detalhado no anexo do relatório do encontro ministerial da OCDE realizado em 2017 (OECD, 2017).

O Brasil já é o país não membro com maior participação em comissões, instrumentos legais e outras atividades da OCDE, e em 2017 o governo formalizou a candidatura oficial do país para se tornar membro efetivo (Mello, 2020). Desde 2007 a OCDE tem seguido uma estratégia de engajamento prioritário (enhanced engagement) em que cinco países parceiros são tidos como parceiros-chave (key partners) para acessão - incluindo Brasil, China, Índia, Indonésia e África do Sul. Porém, apesar de o Brasil ser, segundo OECD (2018), o país mais engajado em cooperação com a OCDE de todos key partners e de todos países que já se candidataram à acessão, o processo não tem avançado significativamente devido a uma divisão entre os membros sobre a velocidade e a forma pela qual deve se dar o processo de alargamento, com os Estados Unidos defendendo uma expansão mais gradual e controlada (Cozendey, 2019). Embora a participação ativa do PCN brasileiro dentro das Diretrizes já contribua a favor da pretensão brasileira de acessão, essa candidatura pode ficar ainda mais fortalecida se houver evidências de que essa participação tem sido efetiva em influenciar o comportamento das empresas multinacionais. Este trabalho usa dados das denúncias junto ao PCN brasileiro e dados do mercado acionário para determinar se existem tais evidências.

O trabalho está estruturado em três seções adicionais. A próxima seção faz uma breve descrição do funcionamento das Diretrizes da OCDE para empresas multinacionais. A seção subsequente descreve a participação brasileira no programa através de dados das denúncias feitas junto ao PCN brasileiro. Finalmente, a última seção realiza testes para determinar se há evidência que essas denúncias afetaram as empresas negativamente. Um efeito negativo sobre as empresas é uma condição necessária para que o programa não seja inócuo e tenha o potencial de induzir um comportamento mais socialmente responsável.

A próxima seção traz a descrição das Diretrizes da OCDE. A seção 3 descreve a natureza e os detalhes dos casos que envolvem empresas e o PCN brasileiros, e a seçáo 4 descreve os métodos usados nos testes. Os testes e os resultados serão descritos na seção 5 e a seção 6 traz as consideraçóes finais.

\section{AS DIRETRIZES DA OCDE PARA CONDUTA CORPORATIVA RESPONSÁVEL}

Uma das principais funçóes da OCDE é estabelecer padróes de governança para facilitar o comércio e a integração global, e as Diretrizes para conduta responsável de empresas multinacionais são um 
dos seus principais programas. Estabelecido em 2000, o programa já passou por diversas revisóes, sendo a última e mais importante em 2011. Neste trabalho, os dados descritivos que usamos incluem todos os casos no histórico do programa, porém, os testes focam nos casos desde 2011, para os quais os dados são melhores e mais uniformes.

Até o final de 2020, 487 casos haviam sido abertos junto ao programa. ${ }^{5}$ As principais áreas de classificação das denúncias são emprego e relaçóes industriais $(23,95 \%)$, políticas gerais $(23,48 \%)$ e direitos humanos $(16,28 \%)$. Nos anos mais recentes houve um aumento no número de casos na área ambiental e de direitos humanos. Em termo de setores, as maiores concentraçôes de denúncias se deram em manufaturas $(24,21 \%)$, mineração e pedreiras $(13,61 \%)$ e outras atividades $(12,97 \%)$.

Empresas multinacionais têm sede em um determinado país, mas operam em vários outros. Assim, as denúncias podem envolver tanto o PCN do país-sede como um ou mais dos países hospedeiros onde a empresa atua. As Diretrizes encorajam a cooperação entre PCNs. Os cinco PCNs mais ativos são o Reino Unido (55 casos), Estados Unidos (48), Países Baixos (39), Brasil (31) e França (31). Já os principais países hospedeiros das empresas denunciadas são os Estados Unidos (36), República Democrática do Congo (35), Brasil (33), Índia (25) e Reino Unido (19). No programa como um todo, os principais denunciantes são as ONGs e os sindicatos, seguidos por indivíduos, sendo que só podem denunciar os que forem efetiva e diretamente afetados pela ação da empresa, ou seu representante formal. Quanto à duração dos casos, mais de metade é resolvida em menos de dois anos, embora vários se arrastem por mais de três ou quatro.

Uma questão importante do programa é conseguir o engajamento da empresa denunciada no processo de mediação com os denunciantes, pois ela não pode ser legalmente forçada a reconhecer a denúncia e a participar dele: a princípio, ela pode simplesmente se recusar a reconhecer ou tomar conhecimento da questáo. A força do programa está na visibilidade que a OCDE pode dar ao caso. Com maior transparência e engajamento possibilitados por mídias sociais, empresas estão cientes da importância que questóes ligadas à responsabilidade corporativa social podem tomar. De todas as denúncias feitas às Diretrizes, $55 \%$ não obtiveram engajamento das empresas. Dos casos que chegaram à medição, desde o início do programa, 32\% resultaram em um acordo total ou parcial, embora alguns dos casos que náo levaram à acordo podem ter sido resolvidos em outras instâncias, como tribunais nacionais. Entretanto, em anos mais recentes, as taxas de engajamento e de acordos têm aumentado. Um dos desafios é justamente conseguir melhorar sua capacidade de fomentar diálogo e acordos entre denunciados e denunciantes.

Para efeito de ilustração dos casos que participam do programa, considere a denúncia contra a companhia de mineração britânica Vedanta, que foi acusada de violar solo sagrado na Índia (Nieuwenkamp, 2013), feita por um grupo de ONGs ao PCN britânico. A recusa da empresa em reconhecer a denúncia e a participar no processo de mediaçáo levou um grupo de investidores institucionais à venda das açóes da empresa dos seus portfólios. Em outro exemplo, a Royal Shell Company foi denunciada em 2011 por três ONGs de haver causado vários derramamentos de petróleo no Niger Delta. A empresa aceitou participar do processo de mediação e colocou como condição para atingir um acordo que as denúncias não fizessem parte de campanhas ou aparecessem no domínio público. As ONGs não aceitaram essas exigências porque, segundo elas, tais campanhas 
são suas principais armas de atuação. ${ }^{6}$ De acordo com Nieuwenkamp (2013, p. 174, tradução nossa), "muitos investidores, como o Fundo Norueguês de Petróleo ou o Fundo de Investimento Calvert dos Estados Unidos, usam as Diretrizes da OCDE para seus investimentos e seriamente consideram as afirmaçóes dos PCNs". ${ }^{7}$

Esses exemplos são casos mais proeminentes escolhidos justamente porque tiveram impactos facilmente reconhecidos. De maneira mais geral, no entanto, é difícil assegurar até que ponto as denúncias são ou não efetivas. Pode haver casos em que a empresa se recusa a participar, mas sofre sançóes do mercado e passa mudar o seu comportamento. Também pode haver casos em que a empresa participa e chega a um acordo, mas náo é atingida de maneira suficientemente forte para mudar suas açôes futuras. É essa dificuldade de medir impacto que torna difícil avaliar o programa a partir de uma simples leitura e tabelamento dos casos. Por isso, em Mueller e Roviello (s.d.) foram usados estudos de eventos, métodos de pareamento (propensity score matching) e um método desenvolvido pelos autores para tentar identificar estatisticamente de maneira mais rigorosa o impacto das denúncias focando onde as firmas mais sentem: no seu lucro. Neste trabalho, aplicamos alguns desses métodos aos casos que envolvem o PCN brasileiro.

\section{A EXPERIÊNCIA BRASILEIRA COM AS DIRETRIZES DA OCDE}

\subsection{Instâncias}

Os dados apresentados no gráfico 1 foram obtidos com o cruzamento da base de dados disponível no site da $\mathrm{OCDE}^{8}$ e do banco de dados de alegaçóes de inobservância do PCN brasileiro. ${ }^{9}$ É importante ressaltar que esse cruzamento foi necessário porque alguns casos que constavam na base do PCN brasileiro não constavam na base da OCDE e vice-versa.

Um caso é definido como uma denúncia contra uma empresa. Se uma denúncia contra várias empresas é apresentada de maneira conjunta, o número de casos é contado como o número de empresas denunciadas. ${ }^{10}$ No total, o PCN brasileiro analisou 43 casos, dos quais 22 já foram concluídos, 11 ainda estáo em curso e 10 não foram aceitos. Vários motivos podem levar o $\mathrm{PCN}$ a não abrir uma instância. No caso da Central Única dos Trabalhadores (CUT) contra a multinacional americana Pertechs, o alegante defendia que a empresa havia demitido injustamente um representante sindical. $\mathrm{O}$ PCN chegou a aceitar o pedido, mas recuou após a decisão de um juiz, que declarou que a companhia havia agido de acordo com a lei. Em outra ocasiáo, a ONG Americans for Democracy and Human Rights in Bahrain alegou que a empresa Condor Non-Lethal Technologies violava as diretrizes ao vender gás lacrimogêneo para o Barém. A falta de provas de que os produtos da empresa tenham causado abuso a direitos humanos e a fonte das alegaçóes - notícias de um blog de um jornalista levaram o PCN a rejeitar a denúncia.

6. 0 caso da Royal Shell está disponível em: <http://mneguidelines.oecd.org/database/instances/nl0018.htm>.

7. "Many investors, like the Norwegian Oil Fund or the US Investment Fund Calvert, use the OECD Guidelines for their investments and take PCN statements very seriously."

8. Disponivel em: <http://mneguidelines.oecd.org/database>.

9. Disponível em: <https://www.gov.br/produtividade-e-comercio-exterior/pt-br/assuntos/camex/NCP/produtos/alegacoes-de-inobservancia> . 10. Em geral, se a denúncia é apresentada de forma conjunta, a OCDE a conta como uma só instância. É por isso que aqui temos mais do que 31 casos. 
GRÁFICO 1

Status de todos os casos analisados pelo PCN brasileiro

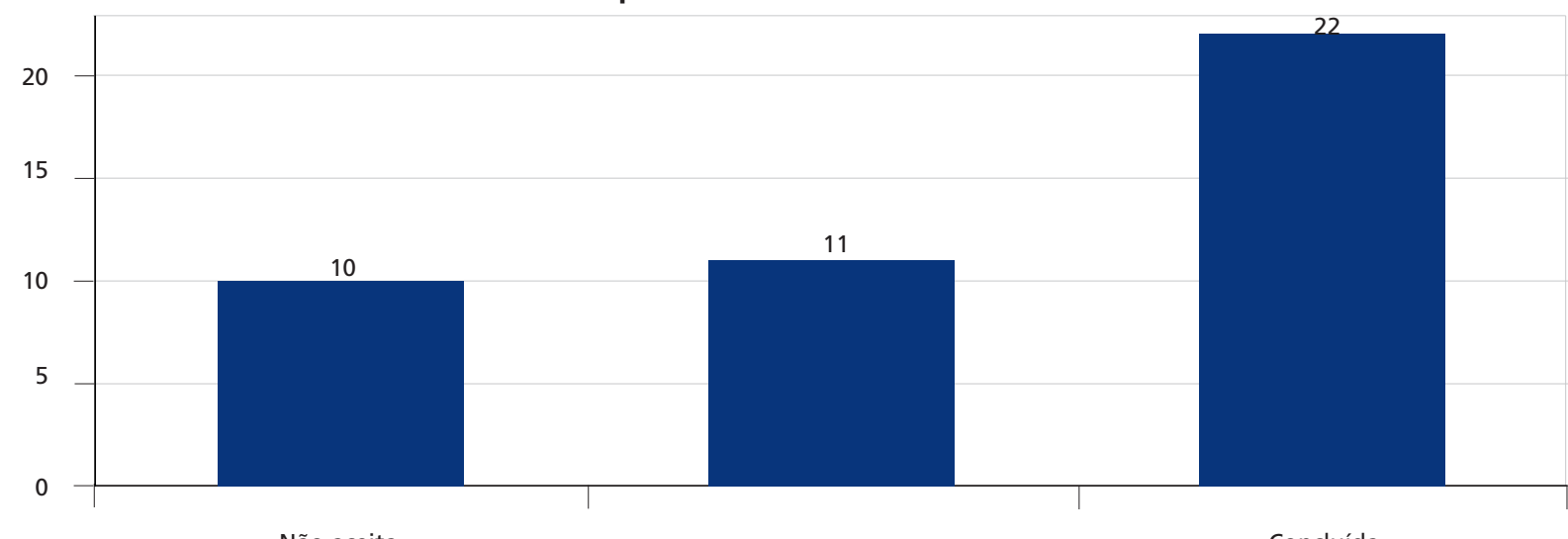

Não aceita

Em curso

Concluída

Fonte: OECD, disponível em: <http://mneguidelines.oecd.org/database/>.

Elaboração dos autores.

Uma vez que o programa busca mediar conflitos relacionados à quebra das diretrizes da OCDE, é possível dividir as instâncias por temas. No total, foi possível identificar nove temas tratados pelo PCN brasileiro, como mostra o gráfico 2. Políticas gerais (29,29\%) foi o mais recorrente, seguido de direitos humanos $(20,20 \%)$, emprego e relaçóes de trabalho $(13,13 \%)$ e meio ambiente $(9.09 \%)$. O gráfico 3 divide os casos por setor, e os três mais recorrentes são atividades financeiras e de seguros' $(17,31 \%)$, mineração $(13,46 \%)$ e agricultura $(13,46 \%)$.

GRÁFICO 2

Instâncias por temas: todos os casos

(Em \%)

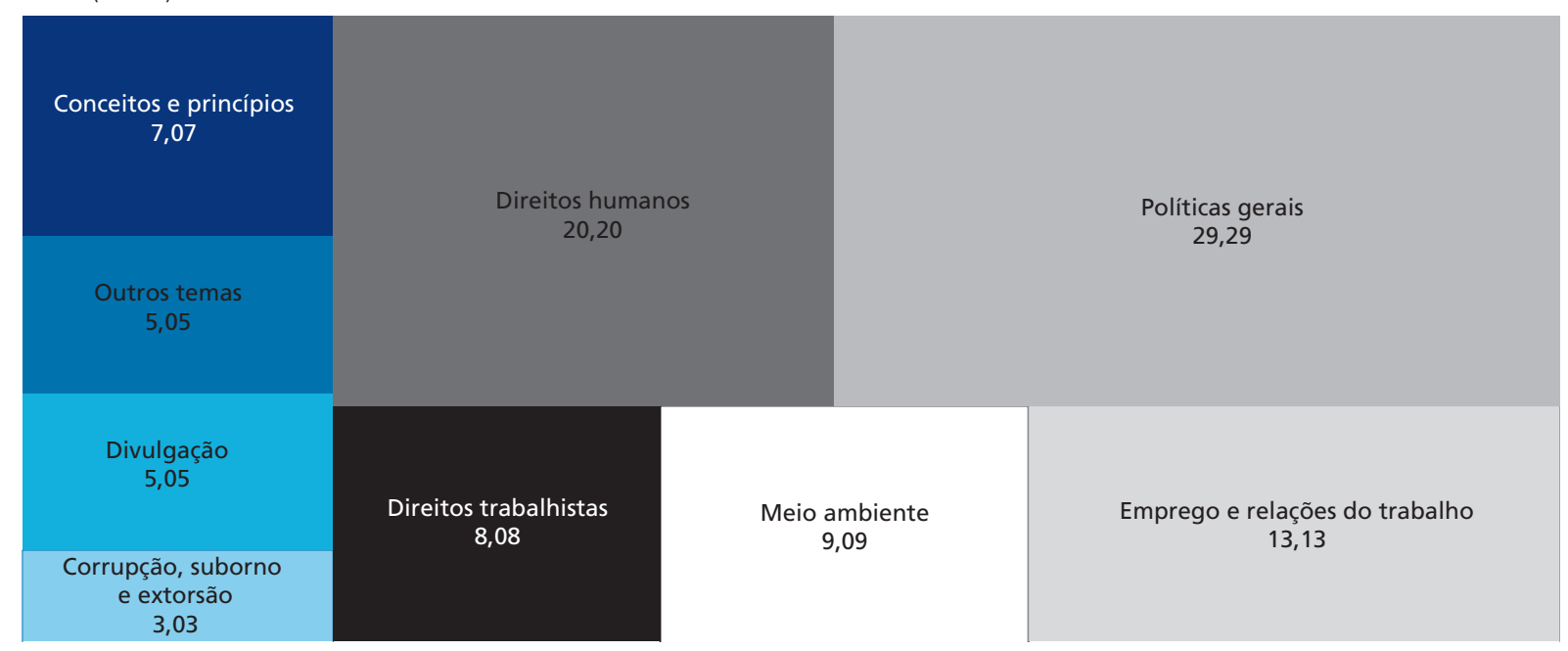

Fonte: OECD, disponível em: <http://mneguidelines.oecd.org/database/>.

Elaboração dos autores. 


\section{GRÁFICO 3}

\section{Instâncias por setor: todos os casos}

(Em \%)

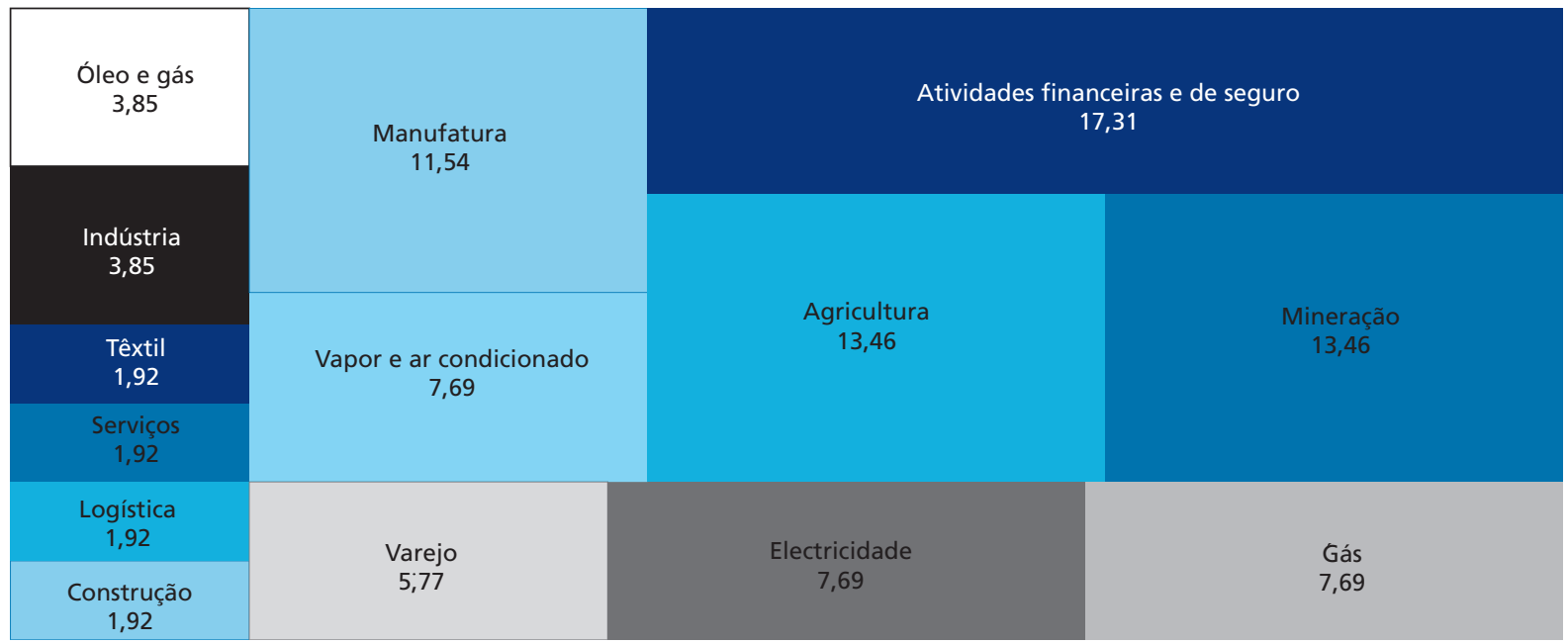

Fonte: OECD, disponível em: <http://mneguidelines.oecd.org/database/>

Elaboração dos autores.

Os denunciantes incluem desde indivíduos até sindicatos. O gráfico 4 contém diferentes categorias de denunciantes, bem como a proporção de cada um em relação ao número de casos totais. No caso brasileiro, a maior parte das alegaçóes foi feita por sindicatos $(53,1 \%)$, seguidos por indivíduos (18,4\%) e ONGs (16,3\%). Aqui, grupo significa um grupo organizado indivíduos que náo um sindicato ou uma $\mathrm{ONG}$, como por exemplo uma associação de moradores.

\section{GRÁFICO 4}

\section{Instâncias por alegante: todos os casos}

(Em \%)

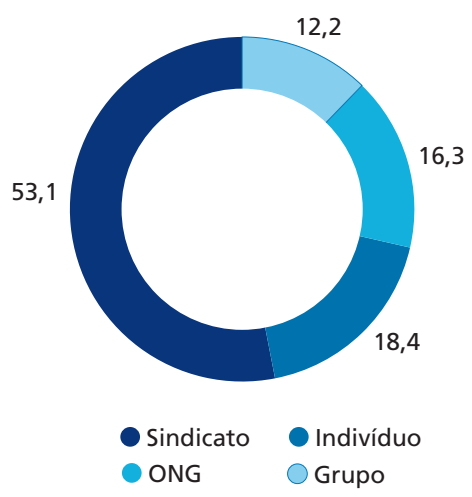

Fonte: OECD, disponivel em: <http://mneguidelines.oecd.org/database/>.

Elaboração dos autores.

É possível que uma mesma instância tenha mais do que um alegante. Por exemplo, é possível que um sindicato e um grupo de ex-trabalhadores façam conjuntamente uma denúncia contra uma firma. O mesmo vale para tema e setor, de modo que um mesmo caso pode ter mais de um tema e se encaixar em mais de um setor. 
Finalmente, o gráfico 5 mostra as empresas denunciadas e quantas vezes o PCN recebeu uma denúncia para uma dada empresa. Nem sempre é possível saber qual empresa foi denunciada devido a acordos de confidencialidade, mas foi possível obter o nome de trinta empresas diferentes. A firma com mais denúncias é a Vale S.A. (quatro denúncias), seguida da Nestlé, Itaú Unibanco, C\&A Modas Ltda, General Motorsm Eni S.p.A. e Banco Santander (duas denúncias cada). Todas as outras empresas foram denunciadas uma só vez.

GRÁFICO 5

\section{Empresas denunciadas}

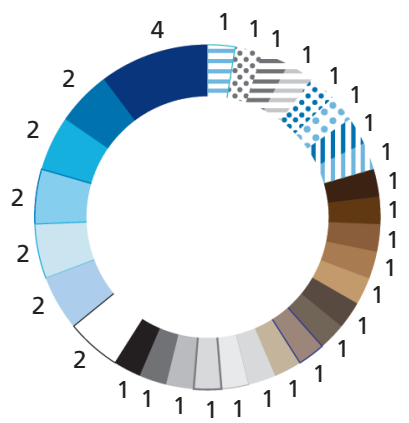

Vale S.A

Nestlé Brasil LTd

Banco Santander S.A

Eni S.p.A.

C\&A Modas Ltda

General Motors do Brasil

OItaú Unibanco S.A.

- Fidelity National BPO Brasil

Atento S.A.

BASF S.A.

Uibanco
Dunkin' Donuts
Jacobs Douwe Egberts
Pertech
Bracell Group
Usina Canabrava
McDonald's
Petrobras
ABN AMRO
BHP-Billiton

Van Oord

- Kinross Brasil Mineração

|| Esso Brasileira de Petróleo

II Banco do Brasil

$\because$ Condor Non-Lethal Technolies

$\therefore$ Illy

= Starbucks

= Unilever

$\therefore$ Shell Brasil

$\ominus$ Mappel

Fonte: $\mathrm{OECD}$, disponivel em: <http://mneguidelines.oecd.org/database/>.

Elaboração dos autores.

\subsection{Duração das instâncias}

O gráfico 6 contém a distribuição da duração para as instâncias que foram concluídas e o 7 mostra a proporção de instâncias para cada classe de duraçáo. Em média, passam-se três anos e três meses da data da denúncia até o encerramento da instância. O caso mais rápido foi o do Sindicato dos Bancários de São Paulo, Osasco e Região contra o Itaú-Unibanco, recebido pelo PCN em dezembro de 2012 e encerrado em abril do ano seguinte. O caso mais longo que foi possível identificar é o da CUT contra a C\&A Modas. A denúncia foi recebida pelo PCN em março de 2007 e se arrastou por mais de setenta meses, até ser encerrada em maio de 2013.

Mais de $40 \%$ das instâncias duram entre um e dois anos, 27,3\% delas duram mais do que cinco anos e apenas 4,5\% duram menos de um ano. A tabela 1 contém estatísticas descritivas sobre o tempo de duração das instâncias que foram concluídas. 


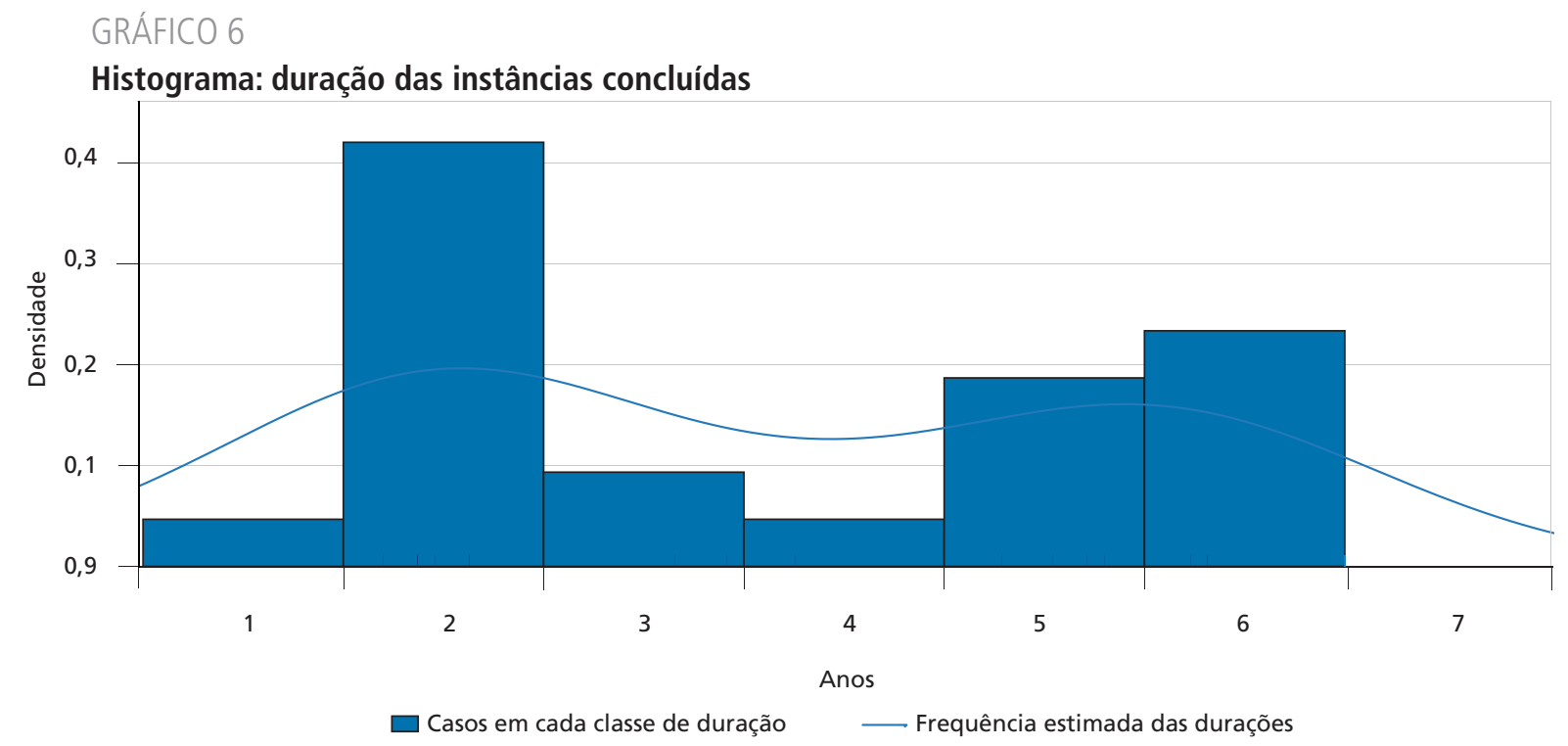

Fonte: OECD, disponivel em: <http://mneguidelines.oecd.org/database/>. Elaboração dos autores.

\section{GRÁFICO 7}

\section{Duração das instâncias}

(Em \%)
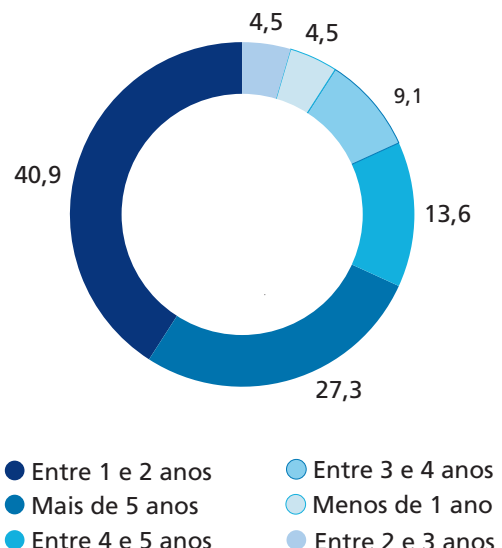

Fonte: OECD, disponível em: <http://mneguidelines.oecd.org/database/>.

Elaboração dos autores.

TABELA 1

Estatísticas descritivas: duração dos casos concluídos

\begin{tabular}{lc}
\hline & Duração \\
\hline Número & 22,00 \\
Média & 3,31 \\
Desvio-padrão & 1,79 \\
Mínimo & 0,33 \\
$25 \%$ & 1,69 \\
$50 \%$ & 3,04 \\
$75 \%$ & 4,98 \\
Máximo & 6,17 \\
\hline
\end{tabular}

Elaboração dos autores. 


\subsection{Acordos e mediações}

Após receber uma denúncia, o PCN confere os documentos e, uma vez que a aceita, oferece seus préstimos como mediador para tentar um acordo. As partes têm a opçáo de aceitar ou não. $\mathrm{O}$ gráfico 8 plota a proporção de casos que terminaram em acordo ou que tiveram mediação nas instâncias da OCDE para sua conclusão. Mais de $90 \%$ dos casos terminaram sem acordo e mais de $77 \%$ sequer resultaram em mediação entre as partes. A baixa taxa de acordos, contudo, não reflete necessariamente a taxa de sucesso do PCN brasileiro.

\section{GRÁFICO 8}

\section{Acordos e mediações: instâncias concluídas} (Em \%)

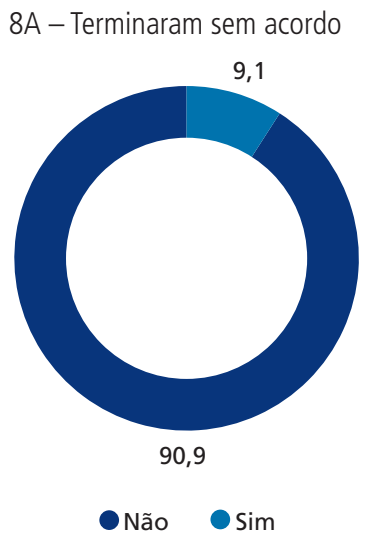

8B - Não tiveram mediação

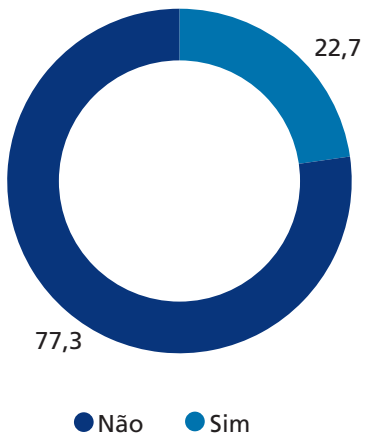

Fonte: OECD, disponivel em: <http://mneguidelines.oecd.org/database/>. Elaboração dos autores.

Um acordo ou mediação é considerado como tal apenas quando ele se dá no âmbito do programa da OCDE - assim, há diversos motivos pelos quais ele pode não ocorrer. Por exemplo, o próprio PCN pode abrir uma instância e depois fechá-la. Isso geralmente ocorre porque o resultado das investigaçóes aponta que as Diretrizes não foram violadas ou porque as partes firmaram um acordo em outra instância que não a OCDE. Esse é o caso da Confederação Nacional dos Trabalhadores do Ramo Financeiro da CUT (CONTRAF/CUT) contra o Unibanco em março de 2007. Apesar das alegaçôes de demissão sem justa causa de um representante sindical, a OCDE encerrou a instância a pedido dos alegantes, que conseguiram chegar a um acordo por meio de negociaçóes diretas. Também é o caso da ONG Coletivo Alternativa Verde e do Sindicato dos Trabalhadores no Comércio de Minérios e Derivados de Petróleo no Estado de São Paulo, que em 2008 alegavam que a Shell e a Esso Brasileira de Petróleo haviam quebrado as diretrizes de políticas gerais e de meio ambiente. A instância acabou encerrada sob o argumento da Shell de que todos os elementos da denúncia já estavam sob análise judicial. ${ }^{11}$

Há casos nos quais o próprio alegante pode solicitar o encerramento de uma instância. Em fevereiro de 2012, a CUT e o Sindicato dos Bancários e Financiários de São Paulo, Osasco e Região denunciaram a empresa Atento S.A. por quebra das Diretrizes da OCDE. A empresa havia respondido

11. A mediação pode ocorrer mesmo quando o processo já está judicializado. Um acordo conseguido via mediação pode inclusive resultar no encerramento do caso na justiça, se, por exemplo, uma parte retirar a queixa. 
às solicitações do NCP, mas os alegantes decidiram encerrar a instância dado que haviam chegado a um acordo com a companhia.

Há, porém, casos de destaque onde o PCN teve sucesso em mediar acordos entre os alegantes e as empresas denunciadas. $\mathrm{O}$ primeiro deles envolve a denúncia de um parlamentar alemão contra a empresa C\&A Brasil. Segundo o alegante, o grupo Cofra e sua subsidiária C\&A Brasil eram co-responsáveis pelo incêndio que destruiu a fábrica Tazreen Fashion em Bangladesh. O incêndio, que deixou 112 mortos e mais de 300 feridos, foi notícia em diversos veículos internacionais e levantou discussóes sobre a violação de normas de segurança do trabalho em países em desenvolvimento. ${ }^{12}$ Mesmo já tendo tomado medidas para mitigar os impactos do incêndio, ${ }^{13}$ em outubro de 2013, quando a alegação foi aceita, a empresa acatou as propostas da OCDE e criou o Programa de Segurança contra Incêndio que, segundo o NCP, tem sido aplicado por fornecedores ao redor do mundo.

Outra alegação que resultou em um acordo foi a de uma associação de moradores de Paracatu, Minas Gerais, contra a mineradora canadense Kinross. Segundo os alegantes, a utilizaçáo de explosivos pela empresa teria danificado as casas do entorno. Além disso, a infraestrutura construída teria dificultado o acesso da área rural da cidade de Machadinho à cidade de Paracatu. Após três reuniooes, a mineradora concordou em reparar as casas danificadas, a despeito de nenhuma relação entre os explosivos e os danos às casas ter sido encontrado.

Em outro caso, em março de 2018, diversos grupos e sindicatos procuraram o PCN brasileiro alegando que a Samarco, uma joint venture entre a Vale S.A. e a BHP Billiton, falhou em compensar as famílias das vítimas do rompimento da barragem do fundão em Mariana, Minas Gerais, ${ }^{14}$ além de não observar as Diretrizes para direitos dos trabalhadores e segurança no trabalho. A tragédia havia deixado dezenove mortes e causado grande dano ambiental. Embora as empresas inicialmente recusassem a mediação, eventualmente houve negociação bem-sucedida.

Esses exemplos mostram que não é possível simplesmente contar o número de acordos para inferir se o programa está tendo sucesso em incentivar um melhor comportamento das empresas em termos de responsabilidade social. Por isso, optamos por usar métodos que consigam detectar se a denúncia afeta o valor das açôes das empresas no mercado acionário. O preço das açóes e seus retornos diários refletem o lucro das empresas, e as empresas por definição são sensíveis a eventos que afetem o seu lucro.

\section{ESTUDOS DE EVENTO: TEORIA E MÉTODOS}

Para averiguar se houve efeito da denúncia da OCDE sobre a empresa denunciada, rodamos estudos de evento com as empresas da amostra cujo preço das açóes estava disponível no site Yahoo Finance para o período de análise. Neste estudo, demos preferência a açóes negociadas na bolsa de valores brasileira, inclusive em forma de Brazilian Depositary Receipts (BDRs). Quando açóes da empresa denunciada não eram negociadas no Brasil, optou-se por usar açóes em bolsas de valores do país de origem de tal companhia. Para cada ação, é possível calcular seu retorno, que é a variação percentual

12. Disponível em: <https://www.nytimes.com/2012/12/18/world/asia/bangladesh-factory-fire-caused-by-gross-negligence.html>; $<$ https://www.bbc.com/news/world-asia-20755952>; <https://edition.cnn.com/2012/11/25/world/asia/bangladesh-factory-fire/index.html>.

13. Disponível em: <https://sustainability.c-and-a.com/pt/pt/sustainability-report/2018/fornecimento-sustentavel/trabalho-justo-e-seguro/> . 14. Disponível em: <https://www.ibama.gov.br/recuperacao-ambiental/rompimento-da-barragem-de-fundao-desastre-da-samarco/documentosrelacionados-ao-desastre-da-samarco-em-mariana-mg>. 
em seu valor em um período de tempo. Retornos positivos significam que o preço da ação aumentou e negativos, que o preço diminuiu. Em geral, açôes acompanham o movimento de suas respectivas bolsas de valores e não sobem ou caem muito além dos índices de mercado. Contudo, choques específicos em uma empresa podem fazer com que suas açôes subam (ou caiam) mais do que o mercado pode prever.

Estudos de evento buscam averiguar se é possível atribuir retornos fora do esperado a eventos onde empresas sofreram choques externos. ${ }^{15}$ Para isso, é preciso "limpar" os retornos de cada ação e depois testar se esse "retorno limpo", que também é chamado de retorno anormal, é diferente ou não de zero. A "limpeza" é feita estimando um modelo no qual os retornos de uma ação são regredidos contra os retornos de um índice de mercado. Os coeficientes obtidos são então utilizados para calcular os retornos anormais, que são os valores reais menos o valor esperado. A ideia fundamental por trás desse método é a hipótese de mercados eficientes Fama (1970), que postula que o mercado acionário rapidamente incorpora ao preço da ação qualquer informação que se torna disponível.

Também é possível somar e tirar a média desses "retornos limpos" para várias empresas ao longo de uma janela de tempo e obter o retorno anormal médio cumulativo (Cumulative Average Abnormal Returns - CAAR). O CAAR nada mais é do que uma estimativa dos retornos fora do esperado para uma ou mais empresas em uma determinada janela de tempo ao redor de uma data, que pode ser diferente para cada empresa. Caso o programa de Diretrizes da OCDE tenha algum efeito sobre as empresas, espera-se que os retornos das açóes, e, portanto, os CAARs, sejam negativos perto da data da denúncia.

O tamanho da janela de tempo na qual o impacto do evento pode ser detectado depende do evento sendo investigado. Devido à rapidez com que os mercados processam informação, as janelas tendem a ser curtas. Além disso, o início da janela muitas vezes se dá antes da data da informação que temos à nossa disposição, por exemplo, a publicação de um artigo no jornal relatando o evento ou a passagem de uma lei. Se o mercado já tinha essa informação antes de ela ser registrada, isso já será refletido nos preços. Assim, por exemplo, o estudo de Flammer (2013), testando o impacto da publicação no Wall Street Journal de notícias sobre açôes de responsabilidade corporativa ambiental por parte de empresas, testou várias janelas em torno da data de publicação e concluiu que a janela de $[-1,0]$ era a mais relevante.

A figura 1 ilustra como os retornos anormais foram calculados. A janela de estimação, que contém os retornos utilizados na regressão, foi de $[-240,-40]$ dias antes da data do evento. Já a janela de análise foi de um dia antes até um dia depois da data do evento. Mais especificamente, os retornos anormais foram estimados com um modelo de mercado, onde $R_{i t}=\alpha_{i}+\beta_{i} R_{m t}+e_{i t}$, onde $R_{i t}$ é o retorno de uma dada empresa em um dia e $R_{m t}$ é o retorno de um índice de mercado em um dia. Os valores esperados são $\hat{R}_{i t}=\hat{\alpha}_{i}+\widehat{\beta}_{l} R_{m t}$. Finalmente, os retornos anormais são calculados como $A R_{i t}=R_{i t}-\hat{R}_{i t}$. 


\section{FIGURA 1}

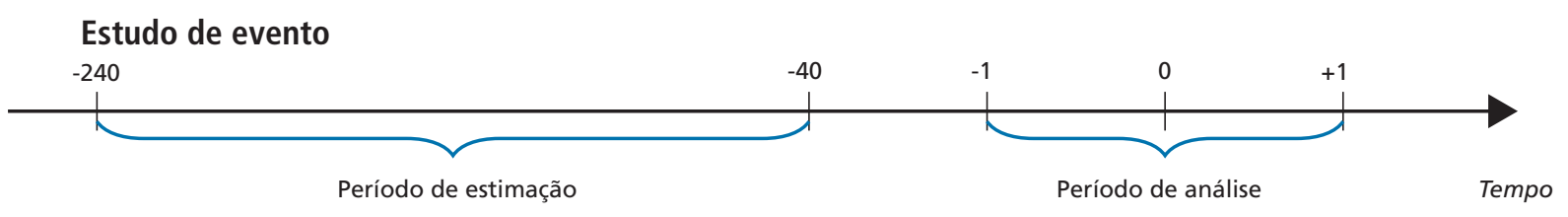

Elaboração dos autores.

Para determinar se os retornos anormais encontrados são estatisticamente diferentes de zero, a abordagem tradicional era um simples teste $t$. No entanto, com a popularizaçáo do método surgiram críticas à capacidade desse teste rejeitar a hipótese nula de ausência de efeito quando realmente há um efeito, ou seja, sua potência. Isso levou à proposição de diversos outros testes e a uma literatura discutindo qual é o teste mais apropriado em diferentes circunstâncias (Gelbach, Helland e Klick, 2013). Em geral, a literatura de estudos de eventos considera dois tipos de testes: paramétricos e não paramétricos. Enquanto testes paramétricos assumem que os retornos são normalmente distribuídos, os não paramétricos não dependem dessa hipótese. Para contornar a possibilidade de não normalidade dos retornos, este estudo utiliza os dois tipos de testes.

Alguns testes paramétricos tendem a rejeitar muito frequentemente a hipótese nula de que os retornos anormais são zero quando um evento causa um aumento na variância dos retornos (Boehmer, Masumeci e Poulsen, 1991). Assim, como teste paramétrico escolhemos o teste de Boehmer, que corrige tal problema. Já como teste não paramétrico, escolhemos o teste de Generalized Rank Test (Grankt). Além de não depender da hipótese de normalidade dos retornos e ter mais poder em amostras pequenas, esse teste é robusto a diversos problemas que retornos podem apresentar, como volatilidade induzida por um evento específico ou autocorrelação dos retornos anormais (Kolari e Pynnonen, 2011).

\section{RESULTADOS}

Para testar do impacto das denúncias, o primeiro passo foi estimar estudos de eventos individuais. O objetivo é verificar como os retornos anormais de cada uma das empresas se comportam quando uma denúncia é feita. Os CAARs são calculados individualmente com respeito à data de sua denúncia e usando o período de estimação [-240, -40] correspondente. A figura 2 plota os CAARs individuais com a data da denúncia no eixo x e o valor do CAAR no eixo $y$. O ticker da açáo marca o valor do CAAR para uma dada empresa e a cor é o setor ao qual pertence a empresa de acordo com o Yahoo Finance. A empresa como menor CAAR foi a de ticker K.TO, que corresponde a Kinross Gold Corporation. A instância que tratou dessa empresa, já citada, foi uma das que terminou em acordo entre alegante e denunciada. O segundo menor CAAR é da empresa Vale S.A. e se refere a uma denúncia feita em janeiro de 2020 acerca do acidente de Brumadinho. De todos os casos levados ao PCN brasileiro, esses são, portanto, os dois em que houve maior impacto negativo aos retornos das empresas na ocasião da denúncia.

A figura 2 não permite que seja concluído definitivamente se as denúncias das empresas brasileiras ao PCN sempre levam a impactos negativos significativos aos retornos, pois metade das empresas está acima do zero e a outra metade, abaixo. No entanto, enquanto quatro das empresas com CAARs positivos estáo a menos de 0,01 do zero, somente duas das empresas negativas estáo nessa situaçáo. 
Nos dois casos comentados anteriormente, as empresas sofreram fortes perdas de valor na janela próxima da data da denúncia.

FIGURA 2

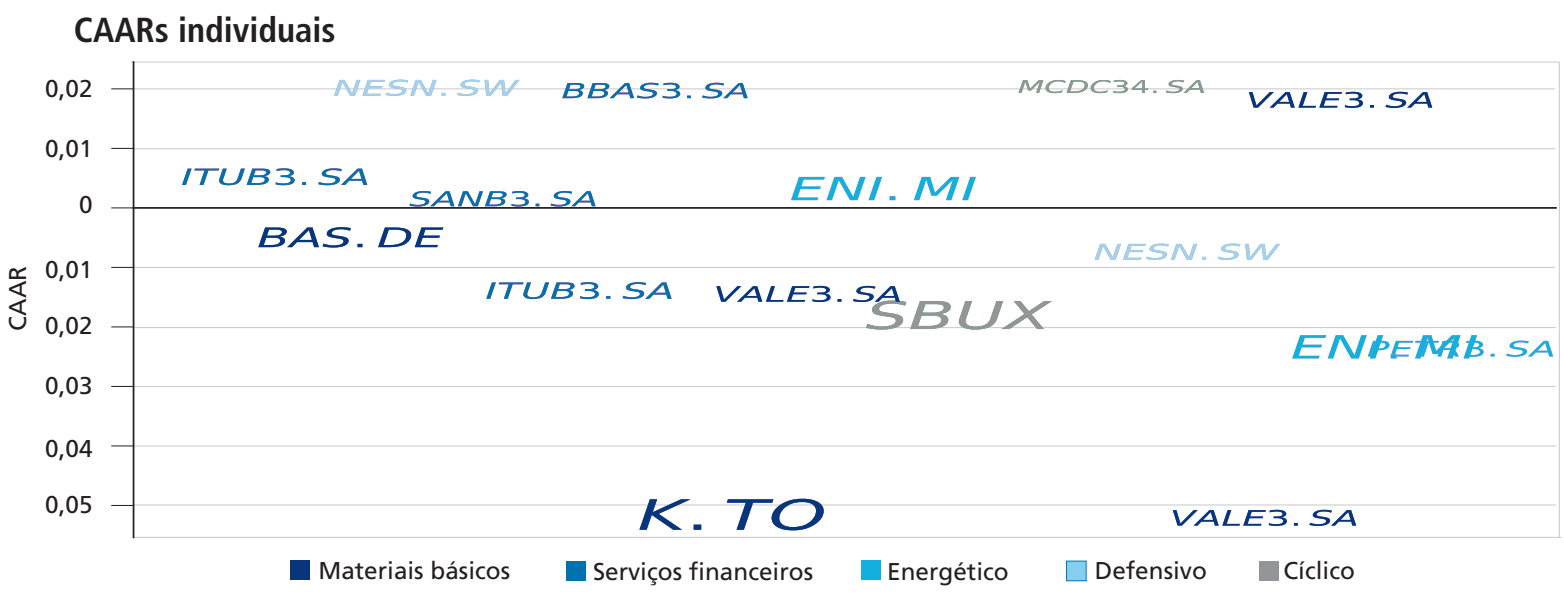

Elaboração dos autores.

Obs.: Relação dos tickers: PETR3.SA - Petrobras; ENI.MI - Eni S.p.A.; VALE3.SA - Vale S.A.; NESN.SW - Nestlé; MCDC34.SA - McDonald's; SBUX Starbucks; K.TO - Kinross Brasil Mineração; BBAS3.SA - Banco do Brasil; ITUB3.SA - Itaú Unibanco S.A.; SANB3.SA - Banco Santander S.A.; BAS.DE - BASF S.A.

Para cada caso, é importante distinguir o efeito do evento que gerou a denúncia do efeito da denúncia em si, pois é possível que o evento gerador da denúncia tenha ou não impacto nos retornos. Brumadinho certamente teve, mas um caso mais simples, como uma instância que trata da demissão de um único funcionário, provavelmente não teve efeito algum. Contudo, nosso interesse não está no evento gerador da denúncia: o que buscamos aqui é verificar se a denúncia para a OCDE tem algum impacto no retorno das açóes. Desse modo, o que chamamos de evento neste estudo não é o fato gerador da denúncia, mas a denúncia em si.

Assim, os impactos estimados são realizados exclusivamente na estreita janela de tempo em torno da denúncia. Os casos de que tratamos se iniciam com eventos que necessariamente antecedem a denúncia, no entanto, há tipicamente um hiato entre o evento original e a denúncia. Portanto, os impactos dos eventos originais já estariam precificados no valor das açôes por ocasião da denúncia, e o evento que nós estamos capturando é a denúncia e não o evento que gerou a denúncia.

Após estimar os CAARs individuais, partimos para a estimação de um estudo de evento contendo as doze empresas da amostra pós-revisão de 2011 para as quais foi possível obter dados, cujos resultados estão na tabela 2. Foram testadas diversas janelas diferentes e em todas elas o retorno anormal médio cumulativo foi negativo. Isso já é uma indicação de que, na média, a aplicação das Diretrizes no caso brasileiro tem um impacto negativo com potencial de sancionar o comportamento corporativo irresponsável. Para determinar se esses impactos negativos são de fato estatisticamente diferentes de zero, usamos os testes de Boehmer e de Grankt. A maioria das janelas na tabela 2 tem CAARs negativos, contudo, somente no caso da janela $[-1,1]$ podemos rejeitar a um nível de $5 \%$ de confiança que esse efeito seja zero usando o teste Grankt. Como são diversas empresas na amostra, cada qual com uma data diferente de denúncia, esse resultado, que está de acordo com os testes que realizamos com a amostra completa de todos os países em Mueller e Roviello (s.d.), dificilmente 
se daria aleatoriamente e podemos, portanto, aceitar que as denúncias têm na média um impacto negativo no lucro das empresas.

TABELA 2

Resultados do estudo de eventos

\begin{tabular}{lllcc}
\hline Janela & $N$ & CAAR & Boehmer (p-valor) & Grankt (p-valor) \\
\hline$[-1 ; 0]$ & 12 & -0.003 & 0.515 & 0.697 \\
{$[-1 ; 1]$} & 12 & $-0.012^{* *}$ & 0.118 & 0.042 \\
{$[-2 ; 0]$} & -0.001 & 0.747 & 0.319 \\
{$[-2 ; 1]$} & 12 & -0.009 & 0.670 & 0.611 \\
{$[-3 ; 1]$} & 12 & -0.007 & 0.613 & 0.534 \\
{$[-3 ; 3]$} & 12 & -0.011 & 0.509 & 0.736 \\
{$[-3 ; 2]$} & 12 & -0.015 & 0.399 & 0.191 \\
{$[-3 ; 0]$} & 11 & 0.001 & 0.892 & 0.567 \\
{$[-5 ; 3]$} & 12 & -0.008 & 0.842 & 0.860 \\
{$[-5 ; 5]$} & 12 & -0.015 & 0.920 & 0.734 \\
\hline
\end{tabular}

Elaboração dos autores.

Obs.: Significância estatística: * $10 \%,{ }^{*} 5 \%,{ }^{* * *} 1 \%$ pelo teste Grankt.

A janela curta em torno do evento está condizente com diversos resultados encontrados na literatura de estudos de evento. As magnitudes podem parecer pequenas, mas é importante lembrar que o Cumulative Abnormal Returns (CAR) é um retorno abnormal do preço das açóes de uma empresa cumulativo no período da janela. Já o CAAR é o CAR médio para todas as empresas da amostra. Assim, o CAAR de -0.012 estimado para a janela $[-1,1]$ significa a perda para os acionistas das empresas denunciadas da amostra de $1,2 \%$ do valor de mercado, na média, devido às denúncias. Como são empresas grandes, esse é um grande impacto. Nosso resultado é, portanto, forte evidência a favor da efetividade da aplicaçáo do programa de responsabilidade corporativa pelo PCN brasileiro nas empresas multinacionais no Brasil.

\section{CONSIDERAÇÕES FINAIS}

Dificilmente programas de responsabilidade social corporativa podem funcionar se dependerem exclusivamente de boas intençóes. Para que as empresas voluntariamente abram mão de comportamentos rentáveis que impóem custos à sociedade, é preciso que percebam que isto trará alguma contrapartida. Esta pode ser uma contrapartida positiva, como a noção de "se dar bem por fazer o bem" (doing well by doing good), em que o mercado premia a empresa por boa conduta. Pode ser também uma contrapartida de reduzir o risco de uma campanha de cancelamento ou boicote devido à percepçáo pelo mercado de alguma violaçáo por parte da empresa. Uma das grandes dificuldades de programas que visam fomentar empresas a adotar açóes de responsabilidade social corporativa é convencer as empresas que sua participação de fato pode gerar estas contrapartidas.

As Diretrizes da OCDE oferecem um grande arcabouço coordenado a nível global para fomentar maiores incentivos para que as grandes empresas multinacionais respeitem princípios de governança social corporativa. Duas décadas após seu início, o programa conta com vários casos de sucesso, mas ao mesmo tempo com uma proporçáo relativamente alta de recusas de engajamento no processo de mediação por empresas denunciadas, assim como casos nos quais nenhum acordo é alcançado. 
Além disso, há grande variabilidade na forma e na diligência com que o programa é implementado por PCNs de diferentes países.

Como o programa depende efetivamente da sua capacidade de impor custos às empresas que violam princípios de CSR, é essencial que exista uma percepção clara que esses custos são uma ameaça crível. $\mathrm{O}$ fato de muitas empresas simplesmente ignorarem as denúncias, se recusando a participar do processo de mediação e negociação, indica que provavelmente essa percepção ainda não está consolidada. Neste trabalho, nós usamos dados dos preços das açôes das empresas denunciadas em torno da data da denúncia para testar se, controlando pelas oscilaçóes gerais do mercado, esse choque específico à empresa tem um impacto negativo. Nosso foco aqui foi nas denúncias realizadas ao PCN brasileiro, e encontramos forte evidência de que, para essa amostra de empresas e denúncias, o programa tem na média um significativo impacto negativo, especificamente na janela $[-1,1] \mathrm{em}$ torno da data da denúncia. Certamente há muito espaço para aprimoramento nas Diretrizes e sua implementação, porém, este resultado mostra que ao menos o programa contém um elemento fundamental que qualquer programa desta natureza necessariamente deve possuir: a capacidade de realizar uma ameaça crível.

\section{REFERÊNCIAS}

BOEHMER, E.; MASUMECI, J.; POULSEN, A. B. Event-study methodology under conditions of event-induced variance. Journal of Financial Economics, n. 30, p. 253-272, 1991.

COZENDEY, C. M. Sobre aceder à OECD. Revista Brasileira de Comércio Exterior, n. 140, 2019.

DAVARNEJAD, L. In the shadow of soft law: The handling of corporate social responsibility disputes under the OECD guidelines for multinational enterprises. Journal of Dispute Resolution, n. 351, 2011.

FAMA, E. F. Efficient capital markets: a review of theory and empirical work. The Journal of Finance, n. 25, v. 2, p. 383-417, 1970.

FLAMMER, C. Corporate social responsibility and shareholder reaction: the environmental awareness of investors. Academy of Management Journal, n. 56, v. 3, p. 758-781, 2013.

FRIEDMAN, M. The social responsibility of business is to increase its profits. In: ZIMMERLI, W. C.; RICHTER, K.; HOLZINGER, M. (Eds.). Corporate ethics and corporate governance, Berlin: Springer, 2007. p. 173-178.

GELBACH, J. B.; HELLAND, E.; KLICK, J. Valid inference in single-firm, single-event studies. American Law and Economics Review, n. 15, v. 2, p. 495-541, 2013.

KOLARI, J. W.; PYNNONEN, S. Nonparametric rank tests for event studies. Journal of Empirical Finance, n. 18, v. 5, p. 953-971, 2011.

KOTHARI, S. P.; WARNER, J. B. Econometrics of event studies. In: ECKBO, B. E. Handbook of empirical corporate finance. North Holland: Elsevier, 2007. p. 3-36.

MELLO, F. D. C. The OECD enlargement in latin america and the Brazilian candidacy. Revista Brasileira de Política Internacional, n. 63, v. 2, 2020.

MUELLER, B.; ROVIELLO, F. Measuring the impact of the OECD Guidelines for responsible business conduct by multinational companies. Brasília: IPEA/CEPAL, s.d.

NIEUWENKAMP, R. The OECD Guidelines for multinational enterprises on responsible business conduct. DQ, n. 171, 2013. 
OECD - ORGANISATION FOR ECONOMIC CO-OPERATION AND DEVELOPMENT. Implementing the OECD Guidelines for multinational enterprises: the national contact points from 2000 to 2015. Paris: OECD, 2016.

Meeting of the OECD council at ministerial level: framework for consideration of prospective members. Paris: OECD, 2017.

Active with Brazil. Paris: OECD, 2018.

RUGGIE, J. G.; NELSON, T. Human rights and the OECD Guidelines for Multinational Enterprises: normative innovations and implementations challenges. Cambridge, MA: HKS, 2015. (Working Paper, n. 66).

THORSTENSEN, V. H.; CORTELLINI, A. C. N.; GULLO, M. F. A OCDE como fórum de governança das empresas multinacionais. São Paulo: FGV, 2018. (Working Paper, n. 488).

WEISSMAN, E. et al. Quantifying the costs, benefits and risks of due diligence for responsible business conduct: framework and assessment tool for companies. Columbia: OECD; SIPA, 2016. 
